\title{
STUDENT TRAINING
}

\section{HIV EDUCATION AND HEALTH CARE STUDENTS - WHERE ARE WE GOING?}

\author{
Lynne M Webber, MB ChB, MMedPath (Virol), DTH \\ Department of Medical Virology, University of Pretoria \\ Penelope A Richards, $P h D$ \\ Department of Anatomy, University of Pretoria \\ Somarie V Grey, DSC \\ Deputy Dean, Faculty of Medicine, University of Pretoria
}

The current status of HIVIAIDS statistics for southern Africa highlights and elevates the plight of health care students, already burdened by the specific nature of their training under the peculiar circumstances now prevailing in South African hospitals and training centres. The everyday and repetitive encounter with the tragedy of HIV/AIDS may well evoke a dangerous and complacent attitude on the part of health care students and a possible non-caring ethos akin to 'HIV fatigue.' Health educators and all members of this profession need to rise to this challenge and ensure health care quality in the age of a changing infectious disease status.

\section{IMPACT OF HIV}

As the 20th anniversary of the first report of an AIDS case in 1981 approaches, HIV poses one of the greatest public health challenges of this era. Whether or not it is or will be the greatest health challenge for mankind remains to be seen or debated; nonetheless the HIV pandemic is of herculean proportion. It has been estimated that more than 40 million people globally were infected with this virus by the end of the year $2000 .^{2}$ In addition, $70 \%$ of those infected live in sub-Saharan Africa. ${ }^{2}$ Analysis of the data from the unlinked anonymous 1999 South African HIV seroprevalence survey of women attending publicly funded antenatal clinics has submitted the following conclusions:

- HIV in South Africa is one of the fastest growing epidemics worldwide

-1 the highest prevalence rates are in women aged 20 - 30 years, and

the HIV prevalence differs for each province, with KwaZulu-Natal exhibiting a rate of $32.5 \%{ }^{2}$

It is not unreasonable to expect that $60-70 \%$ of beds in publicly funded and tertiary hospitals may be occupied by HIV-infected patients. South African health care workers remain at high risk of occupational HIV exposure, illustrated partly by this high HIV prevalence rate. This high risk elevates the plight of health care students, already burdened by the specific nature of their training under the peculiar circumstances now prevailing in South African hospitals and training centres. Although there still exists a dread of acquiring this bloodborne virus, the availability of successful post-exposure prophylaxis (PEP) and the commonplace occurrence of occupational HIV exposure incidents recently seems to have diminished the extent of the often expected horrified reaction to occupational exposure. Worrying as that statement may be, health care students' everyday and repetitive encounter with the tragedy of HIVIAIDS may well evoke a dangerous and complacent attitude and a possible non-caring ethos akin to 'HIV fatigue.' Health educators and all members of this profession need to rise to this challenge and ensure health care quality in the age of a changing infectious disease status. Although this argument may not be a new concept and problem for health care students and practising professionals, the overwhelming nature and high prevalence rate of this epidemic, and its ramifications that involve individual, family and community suffering and the socio-economic and human rights aspects, place the approach to this infection in a unique light.

\section{EVER-CHANGING PERCEPTIONS OF HEALTH CARE STUDENTS}

There can be no doubt that students will work with HIVinfected individuals, and each one will be affected by this disease and long-term illness. Initially and in the recent past, students expressed a variety of feelings and attitudes in their approach to infected patients. ${ }^{4}$ Dread of acquiring the infection as a result of workplace exposure, fear of potential exposure to concomitant and opportunistic infections in immunosuppressed patients, and the lack of skills and emotional burden of dealing with terminally 
diseased young people appeared to be the most dominant emotions. ${ }^{4}$ This HIV epidemic is continuing to evolve in South Africa; it has not yet peaked and students will continue to see its ravages for a considerable period. In turn, the epicentre of the AIDS epidemic is still awaited and health care students will have to be prepared to handle a large and growing number of terminally ill young patients and children as a natural part of their training and future direction.

The recent media attention during and after the XIIIth International AIDS Conference in Durban focused attention firmly on the fact that little has been done to awaken the South African government from its torpor. ${ }^{5}$ In addition, a recent comment in a renowned international journal, Nature Medicine, entitled 'South African government continues policy of inactivity', alluded strongly to issues that were not scientifically addressed, such as reduction of mother-to-child transmission. ${ }^{6}$ Reading about such worrying approaches to matters that form critical components of their training and future attitudes, points to the fact that students need constructive support in order to shape their caring and professional ethos. Real issues have to be tackled by students wherein they deal regularly with HIV-infected patients denied access to treatment and intervention strategies proven to be successful but financially beyond the reach of most infected individuals. Most health care curricula expect the student to know about the latest developments in HIV management, therapy and intervention, yet little may be in place to teach them how to apply this knowledge and the facilities to patients. ${ }^{4}$ These attitudes, together with the possible ethos of HIV fatigue creeping insidiously into the South African health care profession, will impact significantly on student perceptions. In addition, perceptions of a killer disease that is crippling the infrastructure within South Africa will change from the junior to the senior student. These problem areas and others, such as the following, have already been identified by health care educators and students. ${ }^{47}$

\section{SHOULD HIV-POSITIVE HEALTH CARE STUDENTS BE ALLOWED TO CONTINUE THEIR TRAINING?}

This question tends to assess the rights of both the student and patient. Can health care training institutions turn down or stop the training of an individual in a given health care field should they contract HIVIAIDS? Should such institutions, in recognising the potential risk HIV/AIDS poses, be insisting on compulsory HIV testing on a regular basis, despite the individual's constitutional rights? Do patients have the right to refuse treatment or contact with an HIV-infected student? Do only those patients who can afford private care have the right to choose who will care for them? Although most of the questions have clear-cut answers or directions according to the constitutional rights of each South African, they still pose dilemmas that require thought, debate and action.

Who should be responsible for insuring the student against HIV?

The question begs to be asked - should such insurance be compulsory? Considering the economic devastation of this infection coupled with individual expense, it is not unreasonable to expect the training institution to provide such insurance for all individuals in training. Ideally, this cost should be borne by the training institution as part of the safe environment for students. In turn, in the absence of the provision of a safe environment, through no fault of the student, the institution should be prepared to find alternative safeguards. ${ }^{4}$

\section{BY WHOM AND WHEN SHOULD A NATIONAL POLICY BE DEVISED TO ADDRESS THESE EMOTIVE ISSUES?}

Any national policy should be inclusive, therefore it is mandatory that all stakeholders be involved in this process. As students are at the forefront of this issue, strong student leadership is essential. In addition, health care educators, administrators and health care professionals must be consulted. A top-down policy is doomed to failure should bottom-up buy-in not be sought. When one considers all the currently available HIVIAIDS statistics in South Africa, such a policy appears to be long overdue. How can educational values be reinforced?

A major paradigm shift is required among health care educators in order to alter attitudes of students working in surgical and internal medicine environments where HIV/AIDS may feature commonly. Truly integrated curricula, with an emphasis on community and evidence-based health care, go a long way towards encouraging an educationally sound basis to attitude transformation.

However, how do health care educators identify solutions to these problems and still keep such education healthy?

\section{THE ROLE FORWARD FOR HEALTH CARE EDUCATORS}

The Faculty of Medicine at the University of Pretoria has recently devised various action plans to address pertinent issues such as the provision and cost bearing of chemoprophylaxis following occupational exposure to HIV, and voluntary membership for all students and staff of a specifically designed HIV insurance scheme (this was cancelled at the last moment because of technicalities that arose after the promulgation of the new Medical Schemes Act, which caused the underwriters of the scheme to withdraw their support), and it has drawn up a policy 
considering the health care of infected students and professionals.' Yet this is only the beginning, and monitoring of these actions and new directives is required. Relevant data must be compiled, rationally analysed and the knowledge gained fed through to all students and professionals using a continuous reporting system. Quality of health care education can be maintained and improved even in times of change, but this will require a detailed research agenda. ${ }^{8}$ Partnerships must also be nurtured and involve input and output from other faculties and universities. A system must exist for the support of all levels of students and all ranks of professional staff members, incorporating the continuous feedback reporting service that is kept open for discussion (C Coombes, 'HIVIAIDS and the Education Sector Strategic Plan: Education sector planning - learning to live with AIDS' paper prepared for the Educator Sector Strategic Plan First Annual Review Meeting, Maputo, May 1999). Finally, a support structure should also be in place to support and guide HIV-infected students and professionals as well as those burdened and crippled by the impact of HIV on their families, communities and peers.

\section{EDUCATION IN SOUTH AFRICA}

An annual report from the Department of Education has cited that there are 300000 university students, 190000 technikon students and close to 73000 other and support personnel within the education system. ${ }^{9}$ In turn, there are just over 12 million pupils at school (50.5\% female), supported by about 375000 teachers. ${ }^{8}$ Not only are many of these destined to become health care students or participants within the health care system, but many will become victims of this system. Accordingly the impact of HIVIAIDS as a whole on education in South Africa needs to be addressed. Recently, the Youth AIDS Project was launched and has been described as a non-profit project with a board of directors consisting of the deans of the medical schools. Dr Atholl Kent, national director of the Project, has cited the aims in the executive summary, namely to reduce the spread of HIV/AIDS among young South Africans, and to provide them with tools to be compassionate and effective in dealing with HIVIAIDS in their lives and communities. As another part of the Project, medical students will be afforded the opportunity of informing other young South Africans about HIV/AIDS. This Project, and many other initiatives in South Africa and Africa, offer hope, optimism and encouragement. However, attitudes of complacency and hopelessness must be guarded against and again, feedback and data analysis must be readily and frequently available.

\section{CONCLUSION}

The correct and caring attitudes of health care students and professionals must be cherished and should be deemed an urgent and necessary goal for all involved in health care education in South Africa.

\section{REFERENCES}

Levi J. The public health challenges of the HIV epidemic (Editorial). Am J Public Health 2000; 90: 1023-1024.

2. Allen DM, Simelela NP, Makuabalo L Epidemiology of HIV/AIDS in South Africa. The Southern African Journal of HIV Medicine 2000; 1: 9-11.

3. Kramer S. AlDS - still more complacency? Health and Hygiene 2000; 11:26.

4. Pantanowitz $L$, Connell $L$ Attitudes and perceptions of medical and allied medical students towards HIV/AIDS. South Afr J Epidemiol Infect 1996; 11: 99 103.

5. Missed opportunities in Durban (Editorial). Nature Medicine 2000; 6: 839 .

6. Birmingham K. South African government continues policy of inactivity. Nature Medicine 2000; 6: 843 .

Webber LM, Richards PA, Grey SV. HIV prophylaxis: are South African healthcare students being neglected? SAfr J Sci 2000; 96:295-296.

8. Department of Education. Annual Report, 1999. Pretoria: DOE, 2000: 157 - 161.

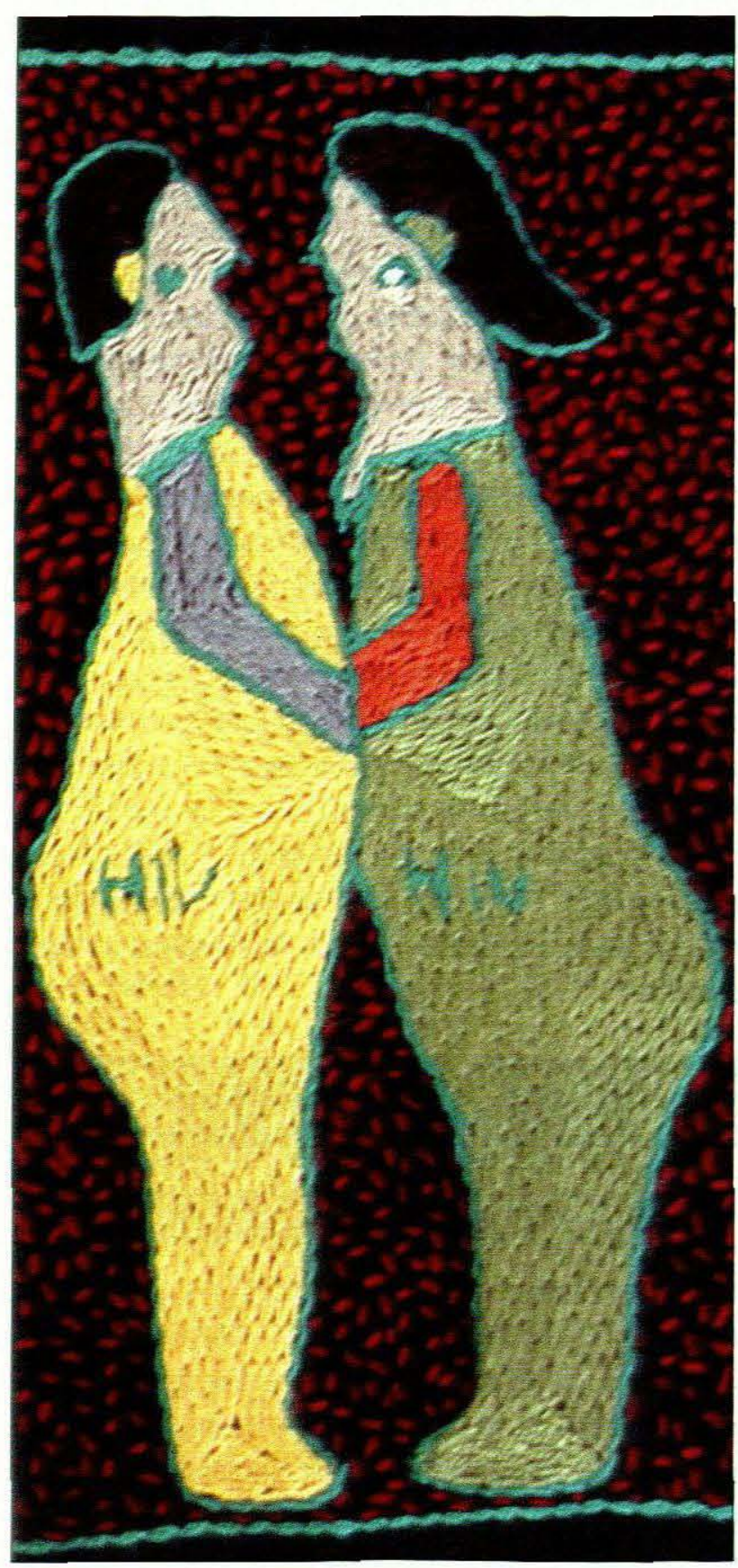

